\title{
EL RECHAZO EN FRONTERA O LA DENOMINADA «DEVOLUCIÓN EN CALIENTE»Y SU REGULACIÓN EN LA LOEX
}

Carmen RuIz SuTIL

Profesora contratada doctora de Derecho internacional privado y acreditada a titular Universidad de Granada

SUMARIO: 1. PLANTEAMIENTO.-2. EL RECHAZO EN FRONTERA Y LA DEVOLUCIÓN COMÚN: SUPUESTOS SEMEJANTES CON TRATAMIENTO DIFERENTE.-3. EL CUMPLIMIENTO DE LA NORMATIVA SOBRE PROTECCIÓN INTERNACIONAL Y EL RECHAZO EN FRONTERA.-4. REFLEXIÓN FINAL.

\section{PLANTEAMiENTO}

La crisis migratoria en Europa pone de manifiesto la imposibilidad de determinados países de regular los flujos de inmigrantes y de refugiados, así como de llevar un control eficiente de las fronteras exteriores europeas. Ello conduce al resurgimiento del debate relativo a las figuras de los retornos inmediatos contemplados en la Declaración UE-Turquía de 20 de marzo de $2016^{1}$, así como las referidas a las devoluciones en caliente (conocidas también como devoluciones sumarias o inmediatas) que diariamente tienen lugar en las fronteras de Ceuta y Melilla. El Comité para la Eliminación de la Discriminación Racial de la Organización de Naciones Unidas (en adelante, ONU), la Agencia de la ONU para los refugiados y otros organismos internacionales critican severamente este tipo de prácticas llevadas a cabo en frontera por considerar que violentan los derechos humanos.

En el caso español, los asaltos masivos de las vallas de Ceuta y Melilla crean preocupación y alarma social, llegando en ocasiones a suscitar situaciones contrarias al orden público. Aunque la singularidad geográfica de Ceuta y Melilla no debe ser un pretexto para eludir las responsabilidades de

\footnotetext{
1 En http://www.consilium.europa.eu/es/press/press-releases/2016/03/18-eu-turkey-statement/ (consultado el 13 de junio de 2016).
} 
España en el cumplimiento de los textos internacionales ratificados ${ }^{2}$, el legislador estatal otorga una respuesta en el ámbito de la coacción administrativa directa de la Administración ${ }^{3}$. Con la figura del rechazo en frontera regulada en la DA 10. a de la Ley Orgánica 4/2000, de 11 de enero ${ }^{4}$, sobre derechos y libertades de los extranjeros en España y su integración social (en adelante, LOEx $)^{5}$, se intenta proporcionar una respuesta inmediata a este tipo de situaciones que acontecen en las ciudades autónomas.

El tema plantea algunos interrogantes no resueltos en relación con el alcance jurídico y, sobre todo, con la adecuación del «rechazo en frontera» a la legislación estatal y a la normativa internacional sobre protección de los derechos humanos de las personas que hayan sido interceptadas en las vallas de Ceuta o Melilla.

En las siguientes páginas trataremos de exponer la problemática planteada, si bien, dadas las características de esta sección, no será posible abordarla con la amplitud deseada. Por esta razón, nos ceñiremos a aquellos aspectos más controvertidos que nos permitan reflexionar sobre el contenido y la realidad de tales devoluciones, teniendo en cuenta la alta dificultad de nuestro país en la gestión de los flujos migratorios en ambas ciudades fronterizas. Y estos mismos motivos nos llevan a excluir el «concepto operativo de frontera» utilizado por el Ministerio del Interior ${ }^{6}$ para sustentar la legalidad de

2 En cuanto a los controles fronterizos de la zona europea, Ceuta y Melilla se exceptuaron del régimen general comunitario a consecuencia de la voluntad conjunta de la UE y del Estado español, que se recogió y expresó en el apartado 1.III del Instrumento de Ratificación de 23 de julio de 1993 del Acuerdo de 25 de junio de 1991 de Adhesión del Reino de España al Convenio de Aplicación de 19 de junio de 1990 del Acuerdo Schengen de 14 de junio de 1985 (BOE núm. 81, de 5 de abril de 1994. Corrección de erratas en $B O E$ núm. 85, de 9 de abril). En similar sentido, el art. 36 y el apartado 21 del Reglamento 562/2006 CE, de 15 de marzo, sobre el código comunitario de normas para el cruce de personas por las fronteras; "Código de fronteras Schengen» (DO L 105/1, de 13 de abril de 2006).

3 La coacción administrativa directa se define como aquella actividad excepcional, pues no ha de quedar otra alternativa, motivada por razones de urgencia o peligro, manifestada a través de un acto administrativo no procedimental y donde debe ser utilizada la fuerza material inmediatamente de forma proporcionada a la necesidad concreta, es decir, la fuerza aplicada directa e inmediatamente sobre una situación de hecho con vistas a producir su modificación sin que se trate de imponer el cumplimiento de un acto administrativo previo declarativo. Veáse AgIRREAZKuENAGA, I., La coacción administrativa directa, Madrid, Civitas, 1990, pp. 50-56.

4 BOE núm. 10, de 12 de enero de 2000.

5 Figura introducida por la Ley 4/2015, de 30 de marzo, de Protección de la Seguridad Ciudadana, BOE núm. 77, de 31 de marzo de 2015. Sobre esta normativa, véase AtMane TlemSANI, T., "Algunas reflexiones en torno a la ley de seguridad ciudadana y el concepto de rechazo en frontera, ¿es adecuada a la normativa internacional sobre derechos humanos?», en http://www.rivistaoidu.net/sites/default/ files/6_Atmane.pdf (consultado el 5 de mayo de 2016).

${ }^{6}$ Que consiste en considerar que el ámbito territorial de soberanía en las playas españolas lo representaría una imaginaria línea formada por los cuerpos de agentes de la Guardia Civil. Por su parte, en las ciudades de Ceuta y Melilla, la zona de soberanía española comienza cuando se atraviesa la valla interior de protección. Para este tema nos remitimos a los términos regulados en la normativa correspondiente y a los informes elaborados por expertos en relación a dicha polémica. Vid. MARTínez Escamilla, M. y SÁnchez Tomás, J. M., «Devoluciones ilegales en la Frontera Sur. Análisis jurídico de las denominadas devoluciones en caliente», febrero de 2015, en http://eprints.ucm.es/28256/1/E\%20 print.\%20DEVOLUCIONES\%20ILEGALES\%20EN\%20LA\%20FRONTERA\%20SUR.pdf (consultada el 11 de mayo de 2016); Martínez Escamilla, M. et al., Informe Jurídico: "Rechazos en frontera»: ¿Frontera 
las llamadas expulsiones/devoluciones en caliente, aunque con la reforma de 2015 de la Ley de extranjería se designa como «elementos de contención fronterizos».

\section{EL RECHAZO EN FRONTERA Y LA DEVOLUCIÓN COMÚN: SUPUESTOS SEMEJANTES CON TRATAMIENTO DIFERENTE}

De la DA $10 .^{a}$ de la LOEx se desprende el término «rechazo en frontera» ${ }^{7}$, que designa a la actuación de las Fuerzas y Cuerpo de Seguridad del Estado respecto de la entrega a las autoridades marroquíes, por vía de hecho, de ciudadanos extranjeros que sean detectados en la línea fronteriza de la demarcación territorial de Ceuta y Melilla mientras intentan superar los elementos de contención fronterizos para cruzar irregularmente la frontera. Este concepto, según rubrica cierta doctrina ${ }^{8}$, en la práctica se extiende además a aquellos extranjeros que de forma indubitada se hallan dentro de las referidas ciudades autónomas. En cualquier caso, la novedad estriba en que la legislación española de extranjería ha introducido un procedimiento especial para el regreso inmediato de estos extranjeros a Marruecos, si bien, el «rechazo en frontera» ya fue utilizado para referirse a los que, no cumpliendo los requisitos para la entrada, pretendían hacerlo por un puesto fronterizo terrestre ${ }^{9}$.

Con frecuencia, el rechazo en frontera suele confundirse con la devolución común prevista en los arts. 58.3 de la LOEx y 23 del Real Decreto 557/2011 ${ }^{10}$, de 20 de abril, por el que se aprueba su Reglamento (en adelante, RLOEx) ${ }^{11}$. Sin embargo, pese a sus similitudes, se trata de una nueva figura que, a diferencia del régimen general vigente de la devolución, no cuenta con un procedimiento en el que se garantice al extranjero el derecho a la tutela judicial

sin derechos? Análisis de la disposición adicional décima de la Ley Orgánica 4/2000, de 11 de enero, sobre derechos y libertades de los extranjeros en España y su integración social, introducida por la Ley Orgánica 4/2015, de 30 de marzo, de protección de la seguridad ciudadana, publicado el 13 de abril, 2015, en http:// eprints.ucm.es/29379/, en esp. p. 318 (consultado el 15 de abril de 2016).

${ }^{7}$ No se hace alusión expresa al rechazo en frontera, sino que se denomina régimen especial de Ceuta y Melilla.

8 Vid. Martínez Escamilla, M. y SÁnchez Tomás. J. M., op. cit., nota 6; Martínez Escamilla, M. et al., op. cit., nota 6 .

9 El rechazo en frontera es la primera medida que se utilizaba contra la inmigración ilegal en la Ley de Extranjería 7/1985, que consistía en la no admisión del extranjero que pretendía entrar en el país por carecer de los requisitos esenciales de entrada. En caso de que el extranjero consiguiera superar dicho filtro, el Estado contaba aún con otra medida contra dichas entradas irregulares, la devolución. Véase Rodríguez Candela, J. L. y García España, E., «La devolución del extranjero», Diario La Ley, 1996, Ref. D-269, t. V, La Ley (La Ley 22585/2001). En la actual la Ley de extranjería, ha derivado en la denegación de entrada recogida en su art. 26.2.

10 BOE núm. 103, de 30 de abril de 2011.

${ }_{11} \mathrm{Al}$ respecto de las garantías previstas en la devolución, véanse los comentarios de la jurisprudencia en HURTADO MARTíNEZ, J. A., «Reflexión sobre la devolución de extranjeros en los puestos fronterizos de Melilla y Ceuta», Revista de Jurisprudencia, 2015, en http://www.elderecho.com/tribuna/administrativo/Reflexion-devolucion-extranjeros-fronterizos-Melilla-Ceuta_11_871930001.html (consultada el 3 de mayo de 2016). 
efectiva en los términos que prescribe el art. 24.1 de la Constitución Españo$\mathrm{la}^{12}$ (en adelante $\left.\mathrm{CE}\right)^{13}$.

La inmediatez que demanda este tipo de situaciones fronterizas es incompatible con el sistema convencional que normalmente culmina con una decisión declarativa previa ${ }^{14}$. Tratándose de una respuesta coactiva directa por parte de la Administración, supone la imposibilidad material de una formalización de los actos administrativos de conformidad con los cánones ordinarios, es decir, con un contenido declarativo previo, notificado por escrito a los interesados y que con posterioridad a su eventual incumplimiento pueda ser ejecutado. Asimismo, es preciso tomar en consideración que con Marruecos nos vincula un Acuerdo bilateral relativo a la circulación de personas, el tránsito y la readmisión de extranjeros entrados ilegalmente ${ }^{15}$, en el que se establece un detallado procedimiento para la entrega de estos extranjeros. De resultar de aplicación el referido texto internacional al rechazo en frontera, en los términos de su art. 2, tras producirse la entrada ilegal del extranjero en nuestro país, la autoridad española quedará obligada a presentar una solicitud de readmisión ante los órganos competentes marroquíes. En dicha petición, entre otras cuestiones, se hará constar las condiciones en que se ha producido la entrada ilegal del extranjero en el territorio español, así como cualquier otra información sobre el mismo.

La falta de claridad sobre este punto ha sido observada por el Defensor del pueblo ${ }^{16}$ y por diversas organizaciones internacionales, como Alto Comisionado de las Naciones Unidas para los Refugiados (en adelante ACNUR) ${ }^{17}$, que vienen recomendando la necesidad de llevar a cabo un procedimiento para el desarrollo reglamentario de la mencionada disposición adicional de la LOEx. Dicho mecanismo deberá contemplar, además de la previa asistencia letrada e intérprete, la adopción de una resolución administrativa que le permita al extranjero defenderse de los cargos imputados, en base al derecho a recurso efectivo que tiene toda persona según el art. 13 de la Convención Europea de Derechos Humanos ${ }^{18}$ (en adelante CEDH) ${ }^{19}$ y de conformidad con la interpretación realizada del art. 106 de la CE. Sobre el alcance de tales preceptos,

12 BOE núm. 311, de 29 de diciembre de 1978.

13 Tal y como viene manifestando el Defensor del Pueblo en su informe de 2016, en https://www. defensordelpueblo.es/wp-content/uploads/2016/02/Informe2015.pdf (consultado el 15 de mayo de 2016).

14 Véase Estrada Carrillo, V., Extranjería, Madrid, Trivium, 1993, pp. 361-362.

15 Firmado en Madrid el 13 de febrero de 1992. La aplicación provisional de este Acuerdo se publicó en $B O E$ núm. 100, de 25 de abril de 1992, y su entrada en vigor definitiva se produjo el 21 de octubre de 2012, en BOE núm. 299, de 13 de diciembre de 2012.

16 En https://www.defensordelpueblo.es/informe-anual/informe-anual-2015 (consultado el 29 de abril de 2016).

17 Agradecemos las conversaciones y la información de la Delegación de ACNUR en España para tener una perspectiva práctica de la temática.

18 Convenio Europeo de Derechos Humanos de 4 de noviembre de 1950 (Consejo de Europa, Treaty Series, núm. 005).

${ }^{19}$ En relación a este derecho, es importante tomar en consideración la Decisión del Tribunal Europeo de Derechos Humanos de 30 de julio de 2015 [N. D. y N. T. c. España (dec.), núm. 2015/75, TEDH 2015], que admite la demanda por posible vulneración del art. 4 del Protocolo 4 y del art. 13 de la 
el Defensor del Pueblo se instruye con la STC 17/2013, de 31 de enero ${ }^{20}$, en la que se analiza la naturaleza de la devolución común prevista en el art. 58.3 LOEx y reconociendo, entre otras cuestiones, que nos encontramos frente a una medida gubernativa de reacción inmediata derivada de una perturbación del orden jurídico, aunque ha sido articulada a través de un cauce flexible y ágil. Ahora bien, ello no significa que la resolución que acuerde la devolución no respete las mínimas garantías previstas en la legislación general sobre el procedimiento administrativo en España.

Tomando como punto de partida estos antecedentes en su conjunto, consideramos que, mientras se articula un procedimiento específico para la mejora del rechazo en frontera, cabría barajar una solución intermedia en la que existan unas mínimas garantías para el regreso del inmigrante a Marruecos. De esta forma, se estaría respetando la agilidad e inmediatez características de este mecanismo fronterizo, al tiempo que se daría aplicación a la mentada normativa internacional. Esta propuesta de mejora no es ajena a nuestro sistema de extranjería. También la figura de la devolución en sus orígenes adolecía de suficientes garantías ${ }^{21}$, carencias que posteriormente han sido salvadas por nuestra norma de extranjería.

\section{EL CUMPLIMIENTO DE LA NORMATIVA SOBRE PROTECCIÓN INTERNACIONAL Y EL RECHAZO EN FRONTERA}

Para reconocer la posibilidad de solicitar la protección internacional, el legislador español realiza una declaración de intención en el apartado 2 de la DA $10{ }^{a}$ de la LOEx, que se integra con el apartado 3 de esta norma. No obstante, la inmediatez con la que opera el rechazo en frontera y la falta de observancia del Acuerdo vigente con Marruecos, como hemos venido advirtiendo, impiden que los extranjeros que asaltan las fronteras de Ceuta y Melilla puedan solicitar protección internacional ante los correspondientes órganos españoles. Aunque se haya introducido en la comentada disposición adicional la posibilidad de pedir el asilo, su ejercicio se diluye ante la carencia de unas garantías básicas e impide que la autoridad española valore la situación individual del extranjero, ni los riesgos que podría correr su regreso a Marruecos 22 .

En todo caso, cuando se realiza el rechazo en frontera y se ven implicados extranjeros que potencialmente pueden ser sujetos de protección inter-

CEDH en sendas «devoluciones en caliente» llevadas a cabo por agentes policiales en la valla fronteriza de Melilla.

${ }^{20}$ Publicada en La Ley 1624/2013, en especial el FJ 12.

${ }^{21}$ Véase Dorado Nogueras, F. M. y Rodríguez Candela, J. L., «Las infracciones en materia de extranjería y su régimen sancionador», en Moya Escudero, M. (dir.), Comentario sistemático a la Ley de extranjería (LO 4/2000 y LO 8/2000), Granada, Comares, 2001, pp. 835-908, en esp. pp. 857-867.

${ }^{22}$ Esta denuncia ha sido evidenciada en numerosas ocasiones por ACNUR, que nos remite a consultar su último comunicado en mayo de 2016 publicado en $h t t p: / / w w w . a c n u r . e s / n o t i c i a s / n o t i c i a s-d e-$ españa/2491/2016-05-27-10-00-19 (consultada el 30 de mayo 2016). 
nacional, el mecanismo establecido por la LOEx no es capaz por sí mismo de discriminar cuando nos encontramos ante una persona susceptible de esta protección. Si esta práctica se sigue efectuando ${ }^{23}$, vulneraría la Convención de Ginebra de 28 de julio de 1951 y del Protocolo de 31 de enero de 1967 sobre el Estatuto de los Refugiados ${ }^{24}$ e impediría el ejercicio del derecho al asilo recogido también en la Ley 12/2009, de 30 de octubre, reguladora del derecho de asilo y de la protección subsidiaria ${ }^{25}$, además de todo el nuevo marco normativo del sistema europeo común de asilo ${ }^{26}$ nacido al amparo del art. 18 Carta de Derechos Fundamentales de la UE ${ }^{27}$. Junto a las garantías para poder requerir la protección internacional, tenemos que vincular el respeto del principio de non refoulement recogido en los arts. 33 de la Convención de las Naciones Unidas sobre el estatuto de los refugiados ${ }^{28}$ y 3 del CEDH, además de todos los instrumentos internacional y europeos que regulan la materia.

Una de las pretensiones del movimiento legislador europeo en materia de asilo es impulsar a que Estados miembros se esfuercen por identificar a los solicitantes que necesitan garantías procedimentales especiales antes de adoptar una resolución judicial, así como prestar un respaldo adecuado cuando piden protección internacional, incluyendo el tiempo necesario para el efectivo acceso a los procedimientos. En este sentido, la Comisión Europea ha analizado la compatibilidad del procedimiento especial del rechazo en frontera en relación con el art. 4, apartado 4, letra b) de la Directiva 2008/115/ CE del Parlamento Europeo y del Consejo, de 16 de diciembre, relativa a normas y procedimientos comunes en los Estados miembros para el retorno de los nacionales de terceros países en situación irregular ${ }^{29}$. La Comisión llega a la siguiente conclusión: «Revisten una importancia fundamental las salva-

${ }^{23}$ Los rechazos en frontera son medidas realizadas casi a diario, tal y como se publica en elfarodigital.es/ceuta/sucesos/188209-ocho-horas-sobre-la-frontera-sur.html (consultada el 5 de junio de 2016).

${ }^{24}$ Instrumento de Adhesión de España en BOE núm. 252, de 21 de octubre de 1978.

25 BOE núm. 263, de 31 de octubre de 2009.

26 Como la Directiva 2013/32/UE, del Parlamento Europeo y del Consejo, de 26 de junio, sobre procedimientos comunes para la concesión o la retirada de la protección internacional (refundición), llamada Directiva de procedimientos y la Directiva 2013/33/UE, del Parlamento Europeo y del Consejo, de 26 de junio, por la que se aprueban normas para la acogida de los solicitantes de protección internacional (de refundición), llamada Directiva de acogida, publicadas ambas en DO L de 29 de julio de 2013, con entrada en vigor el 21 de julio de 2015. Por otra parte, el denominado Reglamento de Dublín regulado por Reglamento (UE) núm. 604/2013, del Parlamento Europeo y del Consejo, de 26 de junio, por el que se establecen los criterios y mecanismos de determinación del Estado miembro responsable del examen de una solicitud de protección internacional presentada en uno de los Estados miembros por un nacional de un tercer país o un apátrida, publicado en DO núm. L 180, el 29 de junio de 2013, aplicable a las solicitudes de protección internacional presentadas desde el 1 de enero de 2014; así como Reglamento (UE) núm. 603/2013, del Parlamento Europeo y del Consejo, de 26 de junio, relativo a la creación del sistema «Eurodac», publicado en DO núm. L 180, de 26 de junio de 2013, y con entrada en vigor el 19 de julio de 2013.

27 DO C 83/391, de 30 de marzo de 2010.

28 Adoptada en Ginebra, Suiza, el 28 de julio de 1951, por la Conferencia de Plenipotenciarios sobre el Estatuto de los Refugiados y de los Apátridas (Naciones Unidas), convocada por la Asamblea General en su Resolución 429 (V), del 14 de diciembre de 1950. Entrada en vigor: 22 de abril de 1954, de conformidad con el art. 43, Serie Tratados de Naciones Unidas, núm. 2545, vol. 189, p. 137.

${ }^{29}$ DOUE L 348/98, de 24 de diciembre. 
guardias contenidas en este procedimiento especial para de Ceuta y Melilla por lo que se refiere a la protección internacional y a la posibilidad de solicitarla en los pasos fronterizos regulares. La reciente creación en las fronteras de Ceuta y Melilla de oficinas en las que los nacionales de terceros países pueden presentar su solicitud de asilo se convierte en un elemento positivo que garantizará el respeto del principio de no devolución».

En definitiva, de lo que se trata es de asegurar una atención apropiada a las necesidades de los extranjeros y, sobre todo, a las personas más vulnerables que vienen huyendo de la persecución sufrida en sus países de origen. Como ya se viera, con el rechazo en frontera esto no está siendo posible, por lo que solo queda esperar la respuesta el Tribunal Constitucional español o de las distintas instituciones judiciales y organismos internacionales (Tribunal de Justicia de la Unión Europea ${ }^{30}$; Tribunal Europeo de Derechos Humanos o por el Comité de Derechos Humanos de Naciones Unidas) con competencia para resolver estos asuntos.

\section{REFLEXIÓN FINAL}

El estudio de la figura del rechazo en frontera requiere de una actuación concertada que permita cohesionar las actuaciones en este punto dentro del espacio de la UE, para de esta forma abrir el camino hacia una política europea de migración y asilo humanitario y eficiente, basada en un reparto justo de las responsabilidades entre los países. El principal reto al que se enfrenta España, dada su condición de única frontera terrestre europea con el continente africano, es, sin duda, la identificación ágil y de diferenciación entre las personas que intentan acceder a Europa de manera irregular de aquellas necesidades de protección internacional. El desafío es complejo cuando existe el intento colectivo de invasión fronteriza por parte de extranjeros no documentados, obligando a la entrada mediante el empleo de la fuerza. Frente a la grave alteración del orden público, las respuesta más inmediata de cualquier legislador es la imposición de medidas correctivas, tal y como sucede con el rechazo en la frontera de nuestra Ley de extranjería.

En este sentido, esperamos que el Reglamento sobre la Guardia Europea de Fronteras y $\operatorname{Costas}^{31}$, así como el avance en la aplicación de los Planes de Acción contra el tráfico ilícito de migrantes ${ }^{32}$ y en materia de retorno ${ }^{33}$ sirvan de ayuda para la gestión de la migración en territorio fronterizo español, y que, con carácter especial, contribuya a la mejora de la situación que protagonizan las ciudades de Ceuta y Melilla.

${ }^{30}$ La apertura por parte de la Comisión Europea de un procedimiento por incumplimiento, en virtud del art. 258 del Tratado de Funcionamiento de la Unión Europea, en DOUE L 83/45, de 30 de marzo de 2010, que podría culminar en un proceso judicial ante el Tribunal de Justicia de la Unión Europea.

$31 \operatorname{COM}(2015) 671$ final.

$32 \operatorname{COM}(2015) 285$ final.

${ }_{33} \operatorname{COM}(2015) 668$ final. 
Palabras clave: inmigración irregular y refugiados, devolución en caliente/retorno inmediato en las ciudades fronterizas de Ceuta y Melilla, el derecho de asilo y el principio de no devolución, legalización de los rechazos en frontera.

Keywords: illegal immigration and refugees, hot returns/immediate return in the cross-border cities of Ceuta and Melilla, the right of asylum and the principle of nonrefoulement, legalizing of the border rejection. 